\title{
Awareness and Knowledge of Low Anterior Resection Syndrome (Lars) in Colorectal Surgeons: A Cross-sectional Survey
}

\section{Sen Hou}

Peking University People's Hospital

\section{Fan Liu}

Peking University People's Hospital

\section{Peng Guo}

Peking University People's Hospital

\section{Yingjiang Ye ( $\nabla$ yeyingjiang@pkuph.edu.cn )}

Department of Gastrointestinal Surgery, Peking University People's Hospital, Beijing 100044, PR China 2: Laboratory of Surgical Oncology, Peking University People's Hospital, Beijing 100044, PR China 3: Beijing Key Laboratory of Colorectal Cancer Diagnosis and Treatment Research, Peking University People's Hospital, Beijing 100044, PR China

\section{Research}

Keywords: rectal cancer, low anterior resection syndrome, defecation dysfunction, surgeons, survey

Posted Date: August 19th, 2020

DOI: https://doi.org/10.21203/rs.3.rs-60968/v1

License: (9) This work is licensed under a Creative Commons Attribution 4.0 International License. Read Full License 


\section{Abstract}

Background More than $50 \%$ patients suffered from low anterior resection syndrome (LARS) after low anterior resection, and their quality of life is predominantly determined by colorectal surgeons' awareness and knowledge of LARS. We conducted the survey to find out the weakness in the management of patients' functional recovery after surgery and explore targeted training pathways to improve doctor's ability to deal with LARS.

Methods An anonymous paper-based survey among colorectal surgeons was performed across the country.

Results 252 questionnaires were collected and analyzed with the effective rate of $86.6 \%$. Most of the respondents were highly educated and experienced in gastroenterology. The mean age was $39.9 \pm 9.20$ years. In multivariate Logistic regression analysis, surgeons with MD, PhD degree (OR: $2.843,95 \% \mathrm{Cl}$ : $1.441-5.609, p=0.003$ ) and national academic membership (OR: 2.063, 95\%Cl: 1.010-4.214, $p=0.047$ ) were associated with surgeons' emphasis on follow-up. $65.1 \%$ of respondents underestimated the prevalence of LARS. Chief/deputy chief, national academic membership and annual surgeries $\geq 50$ ( $42.7 \%$ vs $29.4 \%, p=0.033 ; 46.4 \%$ vs $30.0 \%, p=0.007 ; 46.0 \%$ vs $31.6 \%, p=0.021$ ) were associated with high diagnostic rate of LARS but none of these factors were statistically significant in multivariate analysis. LARS score was the most popular scale in the evaluation of LARS severity. The feedback of the most common postoperative anorectal disorders by colorectal surgeons was significantly different from the items listed in the LARS score. $48.4 \%$ of respondents use drugs to treat LARS but therapies varied from surgeons to surgeons. $C$

onclusions There is a lack of knowledge relating to LARS in colorectal surgeons. Clinical guidelines should be developed to guide medical staff in effective management of patients with LARS.

\section{Backgrounds}

Rectal cancer is one of the most common cancer with the mortality of $3.2 \%$ of cancer death worldwide [1]. The treatment for rectal cancer requires a multidisciplinary approach with surgical resection as the cornerstone of treatment. Fortunately, with the progress of surgical techniques and neoadjuvant therapy, an increasing number of patients accept sphincter-preserving surgery [2]. At present, the mean 5-year survival rate after the treatment of rectal cancer is approximately $65 \%$. If the disease is detected in an early stage, 5-year survival can even be as high as $90 \%$ [3]. 
With increasing survival there is a growing need for knowledge about the long-term side effects and functional results after the treatment [4]. It is reported $52 \%-76 \%$ of patients will suffer anorectal dysfunctions including fecal incontinence, urgency, frequency, constipation from low anterior resections (LAR) withtotal mesorectal excision (TME) $[5,6]$. LAR may modify anorectal anatomy and physiology inevitably and result in postoperative complications $[7,8]$. These combination of abnormal clinical manifestations after LARs was referred as "low anterior resection syndrome (LARS)" [9].

The quality of the assessment is predominantly determined by the instrument administered [10].However, such assessment has been inconsistent due to the lack of a uniform definition of LARS [11], and the use of a large variety of nonvalidated questionnaires [12]. Although the prevalence of LARS is high, evidencebased therapeutic options are not currently available and postoperative strategies varied from surgeons to surgeons [5].

Early diagnosis and treatment of LARS are potential measures to improve quality of life, thus the improvement of colorectal surgeons' knowledge and awareness of LARS is necessary [13]. In this study, a paper-based questionnaire was used to inquire about Chinese colorectal surgeons about their follow-up, assessment, and treatment of patients with LARS. The purpose of this cross-sectional survey was to find out the weakness in the management of patients' postoperative functional recovery and lay the foundation for further doctor training.

\section{Methods}

\section{Study Design and Participants}

This project is designed and carried out between January 2015 and May 2017. 291 colorectal surgeons from twenty-eight regions in mainland China were enrolled in the survey. The formal ethical review was waived by our institutional review board.

\section{Questionnaire}

The questionnaire was sent to surgeons who were older than 25 years, had board certifications and received colorectal specialist training for more than one year. The questionnaire consisted of 13 questions. The questionnaire included the following four parts: (1) general information: gender, age, educational background, clinical title academic membership and hospital categories; (2) surgical information: sub-special (colorectal or surgical oncology), years in practice, the number of LAR completed every year as an surgeon in charge or first assistant,the number of LAR completed in the career, and the most commonly used surgical procedure; (3) follow-up: follow-up methods, the ratio of patients suffered from LARS after LAR as estimated, and the most common chief complaints of bowel dysfunction; (4) assessment and treatment of LARS: the method to assess and treat LARS. To minimize response bias, all the items in the questionnaire are objective questions. The value of "general information" and "surgical information" were encoded only if a single element is checked in each question. However, the options of Q9 and Q11 are not mutually exclusive (Fig. 1). The questionnaires underwent a rigorous scientific review 
to ensure that they are of high quality. Respondents were required to finish the questionnaire within 15 minutes independently. The incomplete questionnaires and those finished overtime were discarded.

\section{statistical analysis}

Characteristic variables were presented as $\mathrm{n}(\%)$, and tested by the chi-square test. Continuous variables were presented as mean \pm SD. Univariate Logistic analysis was conducted for the assessment of factors associated with surgeons' emphasis on follow-up and their opinion on the prevalence of LARS. Variables with a $p<0.1$ were included in the multivariate Logistic analysis which model was constructed. The results of multiple-choice question are shown as frequencies.

All statistics analyses were conducted using SPSS for Windows (version 25.0; IBM Corp., Armonk, NY). A 2 -sided $p<0.05$ was considered statistically significant.

\section{Results}

\section{General information of the respondents}

From January 2015 to May 2017, 291 questionnaires were sent out and 252 were retrieved with an effective rate of $86.6 \%$. 39 questionnaires were discarded because of incomplete information $(n=35)$ and complete the task overtime $(n=4)$. All the colorectal surgeons eventually enrolled were from 28 provinces, autonomous regions and municipalities in mainland China. The mean age was $39.9 \pm 9.20$ years. Most of the respondents $(174 / 252,69.0 \%)$ have worked for more than 5 years as colorectal surgeons. $82.5 \%$ of participates were in tertiary comprehensive hospitals while $11.2 \%$ were from cancer hospitals. There were 62 respondents who completed more than 100 colorectal surgeries annually (Table 1).

\section{Results of follow-up after LAR surgery}

94 doctors said that their medical team would also conduct regular telephone follow-up or regular patient meetings in addition to outpatient follow-up. 124 doctors said that face-to-face follow-up was the only way to know patients' postoperative recovery, and 34 doctors said they never follow up after surgery. 94 respondents with multipath follow-up were regarded as "emphasize follow-up" and the remaining 158 were regarded as "ignore follow-up".

In univariate analysis, surgeons who emphasize follow-up were associated with $\mathrm{MD}, \mathrm{PhD}$ diploma (OR: 2.916, 95\%Cl: 1.719-4.948, p邓0.001), national academic memberships (OR: 2.684, 95\% Cl: 1.587-4.539, $p \rrbracket$ 0.001 ), over 10 years' working experience (OR: $2.495,95 \% \mathrm{Cl}: 1.477-4.214, p \otimes 0.001)$, LAR surgeries $₫ 50$ per year (OR:1.603,95\% Cl: $0.953-2.696, p=0.075)$ and those take laparoscopic or robotic surgery as the most common surgical method (OR: $1.704,95 \% \mathrm{Cl}$ : 1.017-2.857, $p=0.043)$. No differences were observed in age, title, and hospital categories. In the multivariate Logistic regression analysis, MD, PhD degree (OR: $2.843,95 \% \mathrm{Cl}: 1.441-5.609, p=0.003)$ and membership in national academy of gastroenterology (OR: $2.063,95 \% \mathrm{Cl}: 1.010-4.214, p=0.047)$ were associated with consciousness of follow-up (Table 2 ). 
$158(62.7 \%, 158 / 252)$ surgeons reported that defecation dysfunction was less than $50 \%, 94$ surgeons

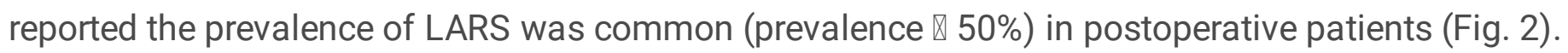

In univariate analysis, surgeons who thought LARS was common were associated with LAR $\geq 50$ every year (OR: 1.846, 95\% Cl: 1.096-3.108, $p=0.021$ ), national academic membership (OR: 2.022, 95\% Cl: 1.204$3.395, p=0.007$ ), and chief/deputy chief title (OR:1.786, 95\%Cl: 1.046-3.049, $p=0.033$ ). No difference was observed in age, educational background, years in practice, hospitals and surgical procedures. In the multivariate Logistic regression analysis, no factor was significant (Table 3).

\section{The common complaints of LARS}

Among the 17 common complains of defecation dysfunction listed in the questionnaire, the most frequently selected options were: incomplete defecation (160/252,63.5\%), loose stool incontinence (138/252,54.8\%), frequent defecation (126/252,50.0\%), constipation (76/252,30.2\%), and urgent defecation (70/252,27.8\%) (Fig. 3).

\section{Assessment and treatment of LARS}

LARS score was the most widely used instrument to assess the severity of LARS (40.6\%), followed by Wexner score (11.3\%), Mark's score (9.0\%), Fecal Incontinence Severity Index (FISI) (6.3\%) and others (1.6\%). $29.7 \%$ of respondents assess the severity of LARS according to the subjective judgement.

Drug was chosen by $48.4 \%$ of surgeons, $26.6 \%$ of respondents prefer traditional Chinese medicine (TCM), $7.0 \%$ of them did not know how to treat with LARS. $5.5 \%$ colorectal surgeons selected radical strategy such as permanent colostomy (Fig. 4).

\section{Discussion}

In this study, a questionnaire was used to investigate the awareness and knowledge of colorectal surgeons on LARS. In this sample of highly educated, rich surgical experience colorectal surgeons in China, some interesting findings regarding their awareness and knowledge of LARS emerge. The major findings of the study were divided into four parts, including colorectal surgeons' follow-up, the frequency of LARS, the assessment and treatment of LARS.

LARS may have a serious adverse impact on the quality of life of patients after rectal cancer surgery. Although most improvements of the functional impairment are known to accomplish by 6 to 12 months after the operation, long-term studies recently reported the duration of symptoms can last up to 15 years after operation $[14,15]$. Plenty of patients are likely to face challenges in recovery, some even have postoperative mental problems which wearing away their quality of life [16]. Some patients have to accept permanent colostomy because of intolerant LARS.Colorectal surgeons are facing serious challenges in the course of follow-up, diagnosis and treatment of LARS. 
LARS usually became apparent after discharge from hospital, and it was important that it can be identified in follow-up. However, postoperative follow-up was completely neglected by a large number of colorectal surgeons (34/252,13.5\%). Appropriate and effective follow-up methods are also very important. There are some inevitable disadvantages in outpatient follow-up. On the one hand, the time of outpatient service are limited, and some patients are unable to elaborate on their abnormal bowel movements. On the other hand, outpatient follow-up may not realize dynamic monitoring on defecation function and some out-of-town patients may not be reviewed by their surgeon in charge. From the above, the effectiveness of traditional outpatient follow-up was dubious. Routine follow-up has been delivered by telephone in some settings. The advantages of telephone follow-up have been well documented $[17,18]$. Telephone consultations may be preferable to patients because itmay improve healthcare quality and decrease patients' burden [19]. In addition, telephone follow-up may decrease outpatient resource use [20]. We believe that doctors who use telephone or regular patients meeting follow-up as a supplement to outpatient emphasize more on postoperative follow-up of LARS. Highly educated surgeons and those joined national academy focus more on follow-up. The reason may be that they have a deeper understanding of LARS, possibly due to their wider access to the latest clinical and research findings. Besides, surgeons who preferred laparoscopic and robotic surgeries emphasized follow-up more. These minimally invasive procedures have been increasing in China recently [21]. Several randomized controlled trials indicated that minimally invasive surgeries showed satisfied short-term and long-term survival, but with less evidence on functional performance [22,23]. Therefore, these surgeons may retrieve functional information via follow-up.

The prevalence of LARS may be underestimated by Chinese colorectal surgeons. Literature shows that more than $50 \%$ of patients with rectal cancer will have different degrees of anorectal disorders after sphincter-preserving surgery [24]. Nevertheless, only 37.3\% (94/252) of surgeons estimated the prevalence of LARS over $50 \%$. In our survey, the frequency of colorectal surgeons encountering LARS patients has no relationship with surgeons' age, degree, clinical title, experience, hospitals and procedures. However, surgeons got membership of national academy and those performed more than 50 rectal cancer surgeries annually meet LARS patients more frequently ( $46.4 \%$ vs $30.0 \%, P=0.007 ; 46.0 \%$ vs $31.6 \%, p=0.021)$. The reason may be that experienced surgeons have better diagnostic ability.

The manifestations of LARS varied. In recent years, the LARS score has been used for quick clinical evaluation of the severity of postoperative defecation dysfunction. In our survey, LARS score was the most popular instrument to evaluate the severity of LARS. LARS score was widely used since it was proposed in 2012 owe to its precision and simplicity [25]. The rating scale ranges from 0 to 42 points and patients are classified into three groups: "no LARS" (0-20 points), "minor LARS" (21-29 points) and "major LARS" (30-42 points). Major LARS was negatively associated with physical, emotional, and social function [13]. The LARS score quantifies the function of defecation from five most important items: incontinence of flatus, Incontinence of liquid stool, frequency, clustering, and urgency [26]. In our investigation, surgeons considered that the five most common defecation disorders were incomplete defection, incontinence for liquid stool, frequency, constipation, and defection urgency. This is not consistent with the five symptoms listed in the LARS score. 160 surgeons $(160 / 252,63.5 \%)$ thought that 
incomplete defecation was the most common symptom, which was not even listed in the LARS score.Similarly, symptoms such as constipation tenesmus and painful defection were also chosen more frequently by surgeons than incontinence of flatus. Incontinence for flatus is the most easily ignored symptom by colorectal surgeons [27], although it is reported that over $40 \%$ of patients faced flatus incontinence affecting quality of life $[28,29]$. Clustering defection, defined as repeated defecation within one hour, was a troublesome postoperative anorectal disorder. Up to $63.2 \%$ of patients undergoing anal preservation surgery with traditional end-to-end anastomosis occurs defection clustering [30], this proportion was still $30 \%$ in patients with modified j-pouch anastomosis [31]. However, defecation clustering has not attracted much attention from colorectal surgeons. There was a significant difference between the items in the LARS score and the defection disorders reported by Chinese colorectal surgeons. The LARS scale was first proposed by European experts, and the scale is based on the characteristics of Caucasians which may not be fully applicable to Chinese patients.

According to the European guideline, no comparative evidence on different treatments for LARS was available [32]. In our survey, nearly half of respondents use drugs to treat LARS but therapies varied from surgeons to surgeons. More than a quarter of respondents suggested patients seeking treatment at TCM. However, there is no reliable evidence-based medical evidence to support this decision. It deserved attention that $7 \%$ surgeons don't know how to treat with LARS and $5.5 \%$ of surgeons were very radical. Surgeries should be an alternative choice only if conservative treatment is ineffective [33].

There are a number of limitations in our survey. Firstly, the sample size is relatively insufficient and the sampling error was inevitable. Secondly, our survey was based on mainland China but it is unsure how well generalizable they are. Thirdly, all of the data were based on colorectal surgeons' subjective opinions and we don't know whether it is correspond to reality. Finally, the thirteen questions listed in the questionnaire may not cover all of the problems related to LARS.

In conclusion, according to our survey, Chinese colorectal surgeons do not pay enough attention to LARS and have insufficient awareness of LARS. It is necessary to strengthen medical education for all colorectal surgeons and guidelines should be developed to guide surgeons in better management of patients with LARS.

\section{Abbreviations}

LAR: Low anterior resection; LARS: Low anterior resection syndrome; TME: Total mesorectal excision; SD:Standard deviation; OR: Odds ratio; MD: Doctor of medicine; MS: Master of science; PhD: Doctor of Philosophy; REF: Reference; Cl: Confidence interval; FISI: Fecal Incontinence Severity Index; TCM:

Traditional Chinese medicine

\section{Declarations}

\section{Acknowledgments}


None.

\section{Competing interests}

None.

\section{Availability of data and materials}

The datasets used and analysed during the current study are available from the corresponding author on reasonable request.

\section{Ethics approval and consent to participate}

The formal ethical review was waived by our institutional review board.

\section{Consent for publication}

Not applicable

\section{Funding}

National Natural and Science Foundation of China (NNSFC): 81871962

\section{Authors' contributions}

Yingjiang $\mathrm{Y}$ designed the research and revised the draft, Sen $\mathrm{H}$ and Peng $\mathrm{G}$ were the main investigators and data recorders, they analyzed and interpreted the data. Sen $\mathrm{H}$ and Fan $\mathrm{L}$ wrote the manuscript together. All authors approved the final version of the manuscript.

\section{Reference}

1. Freddie, Bray, Jacques, Ferlay, Isabelle, Soerjomataram, et al. Global cancer statistics 2018: GLOBOCAN estimates of incidence and mortality worldwide for 36 cancers in 185 countries. CA: a cancer journal for clinicians. 2018.

2. Miller KD, Siegel RL, Lin CC, Mariotto AB, Kramer JL, Rowland JH, et al. Cancer treatment and survivorship statistics, 2016. Ca A Cancer Journal for Clinicians, 2016; 66(4): 271-289.

3. Nuytens F, Develtere D, Sergeant G, Parmentier I, D'Hoore A, D'Hondt M. Perioperative radiotherapy is an independent risk factor for major LARS: a cross-sectional observational study. Int J Colorectal Dis. 2018; 33(8): 1063-1069.

4. Žilinskas J, Jokubauskas M, Smailytė G, Gineikienè I, Tamelis A. Comparison of Changes in DiseaseFree and Overall Survival of Resectable Rectal Adenocarcinoma between 2010 and 2015. Visc Med. 2020; 36(2): 144-149. 
5. Dulskas A, Miliauskas P, Tikuisis R, Escalante R, Samalavicius NE. The functional results of radical rectal cancer surgery: review of the literature. Acta Chirurgica Belgica. 2016; 116(1): 1-10.

6. Keane C, O'Grady G, Bissett I, Woodfield J. Comparison of bowel dysfunction between colorectal cancer survivors and a non-operative non-cancer control group. Colorectal Dis. 2020;22(7):806-813.

7. Farouk R, Duthie GS, Lee PWR, Monson JRT. Endosonographic evidence of injury to the internal anal sphincter after low anterior resection: Long-term follow-up. Diseases of the Colon \& Rectum. 1998; 41(7): 888-891.

8. Fletcher JG, Busse RF, Riederer SJ, Hough D, Gluecker T, Harper CM, et al. Magnetic resonance imaging of anatomic and dynamic defects of the pelvic floor in defecatory disorders. American Journal of Gastroenterology. 2003; 98(2): 399-411.

9. Ziv Y, Bar-Shavit Y, Igov I. Low anterior resection syndrome (LARS): cause and effect and reconstructive considerations. Techniques in Coloproctology. 2013; 17(2): 151-162.

10. Chen TY, Emmertsen KJ, Laurberg S. What Are the Best Questionnaires To Capture Anorectal Function After Surgery in Rectal Cancer? Curr Colorectal Cancer Rep. 2015; 11: 37-43.

11. Bryant CL, Lunniss PJ, Knowles CH, Thaha MA, Chan CL. Anterior resection syndrome. Lancet Oncol. 2012;13(9): e403-408.

12. Scheer AS, Boushey RP, Liang S, Doucette S, O'Connor AM, Moher D. The long-term gastrointestinal functional outcomes following curative anterior resection in adults with rectal cancer: a systematic review and meta-analysis. Dis Colon Rectum. 2011; 54(12): 1589-1597.

13. Kupsch J, Kuhn M, Matzel KE, Zimmer J, Radulova-Mauersberger O, Sims A, et al. To what extent is the low anterior resection syndrome (LARS) associated with quality of life as measured using the EORTC C30 and CR38 quality of life questionnaires? Int J Colorectal Dis. 2019; 34(4): 747-762.

14. Martellucci J. Low Anterior Resection Syndrome: A Treatment Algorithm. Diseases of the Colon \& Rectum. 2016; 59(1): 79-82.

15. Kupsch J, Jackisch T, Matzel KE, Zimmer J, Schreiber A, Sims A, et al. Outcome of bowel function following anterior resection for rectal cancer-an analysis using the low anterior resection syndrome (LARS) score. Int J Colorectal Dis. 2018; 33(6): 787-798.

16. Kwoun HJ, Shin YH. [Impact of Bowel Function, Anxiety and Depression on Quality of Life in Patients with Sphincter-preserving Resection for Rectal Cancer]. J Korean Acad Nurs. 2015; 45(5): 733-741.

17. Starr N, Gebeyehu N, Tesfaye A, Forrester JA, Bekele A, Bitew S, et al. Value and Feasibility of Telephone Follow-Up in Ethiopian Surgical Patients. Surg Infect (Larchmt), 2020. 
18. Bon PL, Solem-Laviec H, Devoueize I, Despres N, Beauplet B. Geriatric phone follow-up in the management of older patients treated for cancer: Telog study results. Journal of Geriatric Oncology, 2020.

19. Thompson JC, Cichowski SB, Rogers RG, et al. Outpatient visits versus telephone interviews for postoperative care: a randomized controlled trial. Int Urogynecol J. 2019;30(10):1639-1646.

20. Thompson-Coon J, Abdul-Rahman AK, Whear R, et al. Telephone consultations in place of face to face out-patient consultations for patients discharged from hospital following surgery: a systematic review. BMC Health Serv Res. 2013;13:128.

21. Ye SP, Zhu WQ, Liu DN, et al. Robotic- vs laparoscopic-assisted proctectomy for locally advanced rectal cancer based on propensity score matching: Short-term outcomes at a colorectal center in China. World J Gastrointest Oncol. 2020;12(4):424-434.

22. Hida K, Okamura R, Sakai Y, et al. Open versus Laparoscopic Surgery for Advanced Low Rectal Cancer: A Large, Multicenter, Propensity Score Matched Cohort Study in Japan. Ann Surg. 2018;268(2):318-324.

23. Kang SB, Park JW, Jeong SY, et al. Open versus laparoscopic surgery for mid or low rectal cancer after neoadjuvant chemoradiotherapy (COREAN trial): short-term outcomes of an open-label randomised controlled trial. Lancet Oncol. 2010;11(7):637-645.

24. Juul T, Ahlberg M, Biondo S, et al. Low anterior resection syndrome and quality of life: an international multicenter study. Dis Colon Rectum. 2014;57(5):585-591.

25. Emmertsen KJ, Laurberg S. Low Anterior Resection Syndrome Score Development and Validation of a Symptom-Based Scoring System for Bowel Dysfunction After Low Anterior Resection for Rectal Cancer. Annals of Surgery. 2012;255(5): 922-928.

26. Emmertsen KJ, Laurberg S. Low anterior resection syndrome score: development and validation of a symptom-based scoring system for bowel dysfunction after low anterior resection for rectal cancer. Ann Surg. 2012;255(5):922-928.

27. Chen TY, Emmertsen KJ, Laurberg S. Bowel dysfunction after rectal cancer treatment: a study comparing the specialist's versus patient's perspective. BMJ Open. 2014;4(1):e003374.

28. van Heinsbergen $M$, Van der Heijden JAG, Stassen LP, et al. The low anterior resection syndrome in a reference population: prevalence and predictive factors in the Netherlands. Colorectal Dis. 2020;22(1):4652.

29. Vironen JH, Kairaluoma M, Aalto AM, Kellokumpu IH. Impact of functional results on quality of life after rectal cancer surgery. Dis Colon Rectum. 2006;49(5):568-578. 
30. Ho YH, Tan M, Leong AF, Seow-Choen F. Ambulatory manometry in patients with colonic J-pouch and straight coloanal anastomoses: randomized, controlled trial. Dis Colon Rectum. 2000;43(6):793-799.

31. Dehni N, Tiret E, Singland JD, et al. Long-term functional outcome after low anterior resection: comparison of low colorectal anastomosis and colonic J-pouch-anal anastomosis. Dis Colon Rectum. 1998;41(7):817-823.

32. Colorectal cancer NICE guideline [NG151]. Available from: https://www.nice.org.uk/guidance/ng151. Accessed January 29, 2020.

33. McKenna NP. Low Anterior Resection Syndrome. Dis Colon Rectum. 2019;62(12):1420-1422.

\section{Tables}

Table 1. General information of the respondents 


\begin{tabular}{|c|c|}
\hline Characteristics & $\mathrm{n}(\%)$ \\
\hline Total & $252(100)$ \\
\hline Age(year) & $39.9 \pm 9.2$ \\
\hline Sex (Male) & $250(99.2)$ \\
\hline \multicolumn{2}{|l|}{ Education background } \\
\hline MD & $44(17.4)$ \\
\hline MD, MS & 104(41.3) \\
\hline MD, PhD & 104(41.3) \\
\hline \multicolumn{2}{|l|}{ Titles } \\
\hline Resident & $54(21.4)$ \\
\hline Attending & $54(21.4)$ \\
\hline Deputy chief & $58(23.0)$ \\
\hline Chief & $86(34.1)$ \\
\hline \multicolumn{2}{|l|}{ Memberships of enterology } \\
\hline National & 112(44.4) \\
\hline Provincial & $26(10.3)$ \\
\hline Municipal & $40(15.9)$ \\
\hline None & $74(29.4)$ \\
\hline \multicolumn{2}{|l|}{ Years in practice } \\
\hline$\otimes 5$ & 78(31.0) \\
\hline $5-10$ & $54(21.4)$ \\
\hline $10-20$ & $52(20.6)$ \\
\hline$\otimes 20$ & $68(27.0)$ \\
\hline \multicolumn{2}{|l|}{ Hospitals } \\
\hline Tertiary comprehensive hospital ${ }^{a}$ & $208(82.5)$ \\
\hline Tertiarycancer hospital $^{a}$ & $26(10.3)$ \\
\hline Primary comprehensive hospital ${ }^{b}$ & $16(6.3)$ \\
\hline Primarycancer hospital ${ }^{b}$ & $2(0.9)$ \\
\hline
\end{tabular}




\begin{tabular}{|ll|}
\hline 20 & $120(47.6)$ \\
\hline $20-50$ & $32(12.7)$ \\
\hline $50-100$ & $38(15.1)$ \\
\hline 100 & $62(24.6)$ \\
\hline Primary surgical procedure & \\
\hline Open surgery & $144(57.1)$ \\
\hline Laparoscopic surgery & $98(38.9)$ \\
\hline Robotic surgery & $10(4.0)$ \\
\hline
\end{tabular}

Statistics presented as mean \pm SD, or $N(\%)$

MD: Doctorofmedicine;MS: Master of science;PhD: Doctor of Philosophy

Tertiaryhospital ${ }^{\text {a: }}$ Large and advanced hospitals providing medical and health services across the whole country, with more than 500 beds.

Primary hospital ${ }^{\mathrm{b}}$ : Regional hospital providing health services across several communities, with 100-499 beds. 
TABLE 2. Logistic regression analysis of associated factors ofsurgeons' emphasison follow-up.

\begin{tabular}{|c|c|c|c|c|c|}
\hline & \multirow{2}{*}{$\begin{array}{l}\text { Emphasize } \\
\text { follow-up }\end{array}$} & \multicolumn{2}{|c|}{ Univariate Analysis } & \multicolumn{2}{|c|}{ Multivariate Analysis } \\
\hline & & OR $(95 \% \mathrm{Cl})$ & $\begin{array}{l}p- \\
\text { value }\end{array}$ & OR $(95 \% \mathrm{Cl})$ & $\begin{array}{l}p \text { - } \\
\text { value }\end{array}$ \\
\hline Age(year) & & & 0.854 & & \\
\hline$₫ 45$ & $62(36.9)$ & REF & & & \\
\hline$\geq 45$ & $32(38.1)$ & $\begin{array}{l}1.052(0.613- \\
1.806)\end{array}$ & & & \\
\hline Education background & & & 00.001 & $\begin{array}{l}2.843(1.441- \\
5.609)\end{array}$ & 0.003 \\
\hline $\mathrm{MD} / \mathrm{MS}$ & $40(27.0)$ & REF & & & \\
\hline $\mathrm{MD}, \mathrm{PhD}$ & $54(51.9)$ & $\begin{array}{l}2.916(1.719- \\
4.948)\end{array}$ & & & \\
\hline Titles & & & 0.990 & & \\
\hline Residents / Attending & $38(37.3)$ & REF & & & \\
\hline Deputy chief / Chief & $56(37.3)$ & $\begin{array}{l}1.003(0.596- \\
1.688)\end{array}$ & & & \\
\hline $\begin{array}{l}\text { National academic } \\
\text { membership }\end{array}$ & & & 00.001 & $\begin{array}{l}2.063(1.010- \\
4.214)\end{array}$ & 0.047 \\
\hline No & $44(28.9)$ & REF & & & \\
\hline Yes & $50(50)$ & $\begin{array}{l}2.684(1.587- \\
4.539)\end{array}$ & & & \\
\hline Years in practice & & & 00.001 & $\begin{array}{l}1.173(0.558- \\
2.464)\end{array}$ & 0.674 \\
\hline$\nabla 10$ & $36(27.3)$ & REF & & & \\
\hline$\geq 10$ & $58(48.3)$ & $\begin{array}{l}2.495(1.477- \\
4.214)\end{array}$ & & & \\
\hline Hospitals & & & 0.314 & & \\
\hline Comprehensive & $86(38.4)$ & REF & & & \\
\hline Cancer & $8(28.6)$ & $\begin{array}{l}0.642(0.271- \\
1.521)\end{array}$ & & & \\
\hline $\begin{array}{l}\text { Number of LAR (case / } \\
\text { year) }\end{array}$ & & & 0.075 & $\begin{array}{l}0.584(0.289- \\
1.182)\end{array}$ & 0.135 \\
\hline$\nabla 50$ & $50(32.9)$ & REF & & & \\
\hline$\geq 50$ & $44(44.0)$ & $1.603(0.953-$ & & & \\
\hline
\end{tabular}


Statistics presented as N (\%) or OR $(95 \% \mathrm{Cl})$

MD: Doctor of medicine; MS: Master of science; PhD: Doctor of Philosophy; REF: Reference; OR: Odds ratio; Cl: Confidence interval. 
TABLE 3. Logistic regression analysis of factors associated with colorectal surgeons' estimatefor theprevalenceof LARS in postoperative patients

\begin{tabular}{lllll} 
LARS is & \multicolumn{2}{l}{ Univariate Analysis } & \multicolumn{2}{l}{ Multivariate Analysis } \\
common & OR $(95 \% \mathrm{Cl})$ & $\begin{array}{l}p- \\
\text { value } \\
\begin{array}{l}\text { prevalence } \\
50 \%)\end{array}\end{array}$ & OR $(95 \% \mathrm{Cl})$ & $\begin{array}{l}p- \\
\text { value }\end{array}$ \\
& & & &
\end{tabular}

Age(year)

0.461

$₫ 45$

60(35.7)

REF

$\geq 45$

34(40.5)

$1.224(0.715-$

2.096)

Education background

0.750

$\mathrm{MD} / \mathrm{MS}$

54 (36.5)

REF

MD, PhD

40 (38.5)

1.088 (0.648-

1.826)

Titles

0.033

1.125 (0.559-

2.262)

0.741

$\begin{array}{lll}\text { Resident / Attending } & 30(29.4) & \text { REF } \\ \text { Deputy chief/ Chief } & 64(42.7) & \begin{array}{l}1.786(1.046- \\ \text { 3.049) }\end{array}\end{array}$

National

academicmemberships

$\begin{array}{ll}\mathbf{0 . 0 0 7} & 1.656(0.887- \\ & 3.090)\end{array}$

0.113

No

42 (30.0)

REF

Yes

52(46.4)

2.022 (1.204-

3.395)

Years in practice

$\begin{array}{lll}\text { Q10 } & 44(33.3) & \text { REF } \\ \geq 10 & 50(41.7) & 1.429(0.856- \\ & & 2.385)\end{array}$

Hospitals

0.519

Comprehensive

82 (36.6)

REF

Cancer

$12(42.9)$

$1.299(0.586-$
$2.880)$

Numbers of LAR (case / year)

0.021

$1.410(0.754-$

0.282

$₫ 50$

48 (31.6)

REF 


$\begin{array}{lll}\geq 50 & 46(46.0) & 1.846(1.096- \\ & & 3.108)\end{array}$

Surgical procedure 0.652

Open surgery

$52(36.1)$

REF

Laparoscopic / robotic surgery

$42(38.9)$

$1.126(0.673-$

1.884)

Statistics presented as $\mathrm{N}(\%)$ or OR $(95 \% \mathrm{Cl})$

MD: Doctorofmedicine; MS: Master of science; PhD: Doctor of Philosophy; REF: Reference; OR: Odds ratio; Cl: Confidence interval.

\section{Figures}




\section{Colorectal Surgeon Reported Questionnaire}

\begin{tabular}{|c|c|c|c|c|c|}
\hline \multicolumn{6}{|c|}{ GENERAL INFORMATION } \\
\hline Name & Age & & Sex & Female & \\
\hline \multicolumn{2}{|c|}{ Q1: Education background (Degree) } & \multicolumn{4}{|c|}{$\square \mathrm{MD}, \mathrm{PhD}$} \\
\hline \multicolumn{2}{|c|}{ Q2: What is your clinical title? } & $\square$ Resident & $\square$ Attending & $\square$ Deputy chief & $\square$ Chief \\
\hline \multicolumn{2}{|c|}{ Q3: Do you have academic memberships? } & $\square$ National & $\square$ Provincial & $\square$ Municipal & $\square$ None \\
\hline \multicolumn{2}{|c|}{ Q4: Which kind of hospitals are you working in? } & \multicolumn{4}{|c|}{$\begin{array}{ll}\square \text { Tertiary comprehensive hospital } & \square \text { Tertiary cancer hospital } \\
\square \text { Primary comprehensive hospital } & \square \text { Primary cancer hospital }\end{array}$} \\
\hline \multicolumn{6}{|c|}{ SURGICAL INFORMATION } \\
\hline \multicolumn{2}{|c|}{$\begin{array}{l}\text { Q5: How many years have you been in colorectal } \\
\text { practice? }\end{array}$} & $\square<5$ & $\square 5-10$ & $\square$ व $10-20$ & $\square>20$ \\
\hline \multicolumn{2}{|c|}{$\begin{array}{l}\text { Q6: How many low anterior resections surgeries } \\
\text { have you finished in your career? }\end{array}$} & $\square<50$ & $\square$ 50-100 & $\square$ 100-200 & $\square>200$ \\
\hline \multicolumn{2}{|c|}{$\begin{array}{l}\text { Q7: How many low anterior resections have you } \\
\text { finished every year? }\end{array}$} & $\square<50$ & $\square 50-100$ & $\square$ 100-200 & $\square>200$ \\
\hline \multicolumn{2}{|c|}{$\begin{array}{l}\text { Q8: Which is the most common used surgical } \\
\text { procedure? }\end{array}$} & $\square$ Open & $\square$ Laparoscopic & $\square$ Robotic & \\
\hline \multicolumn{6}{|c|}{ FOLLOW-UP } \\
\hline \multicolumn{2}{|c|}{$\begin{array}{l}\text { Q9: Which method do you use in follow-up? } \\
\text { (Indefinite selection) }\end{array}$} & \multicolumn{4}{|c|}{$\begin{array}{l}\square \text { No follow-up } \quad \square \text { Outpatient } \quad \square \text { Telephone } \\
\square \text { Regular patient meetings } \quad \square \text { Others: (Please specify) }\end{array}$} \\
\hline \multicolumn{2}{|c|}{$\begin{array}{l}\text { Q10: How many patients suffer from LARS after } \\
\text { low anterior resection as you estimated? }\end{array}$} & \multicolumn{2}{|c|}{$\begin{array}{l}\square \text { Seldom }(0-25 \%) \\
\square \text { Common }(50 \%-75 \%)\end{array}$} & \multicolumn{2}{|c|}{$\begin{array}{l}\square \text { Not common }(25 \%-50 \%) \\
\square \text { Almost all }(>75 \%)\end{array}$} \\
\hline \multicolumn{2}{|c|}{$\begin{array}{l}\text { Q11: Which are the most common chief } \\
\text { complains of bowel dysfunction? (Indefinite } \\
\text { selection but no more than FIVE items) }\end{array}$} & \multicolumn{2}{|c|}{$\begin{array}{l}\square \text { Clustering } \\
\square \text { Force defection } \\
\square \text { Incontinence of liquid stool } \\
\square \text { Incomplete defection } \\
\square \text { Overnight defection } \\
\square \text { Painful defection } \\
\square \text { Urgency } \\
\square \text { Underwear pollution } \\
\square \text { Viscous defection }\end{array}$} & \multicolumn{2}{|c|}{$\begin{array}{l}\square \text { Constipation } \\
\square \text { Frequency } \\
\square \text { Incontinence of flatus } \\
\square \text { Incontinence of solid stool } \\
\square \text { Obstructive defection } \\
\square \text { Prolonged defection } \\
\square \text { Tenesmus } \\
\square \text { Use paper diaper }\end{array}$} \\
\hline \multicolumn{6}{|c|}{ ASSESSMENT \& TREATMENT } \\
\hline \multicolumn{2}{|c|}{$\begin{array}{l}\text { Q12: Which method do you use to assess the } \\
\text { severity of bowel dysfunction? }\end{array}$} & $\begin{array}{l}\square \text { LARS score } \\
\square \text { Mark's score }\end{array}$ & $\begin{array}{l}\square \text { FISI } \\
\square \text { Wexner score }\end{array}$ & $\begin{aligned} & \square \text { Subjecti } \\
& \text { ore } \quad \square \text { Others: }(\end{aligned}$ & $\begin{array}{l}\text { e judgement } \\
\text { lease specify) }\end{array}$ \\
\hline Q13: H & & $\begin{array}{l}\square \text { Don't know } \\
\square \text { Drug } \\
\square \text { Biofeedback }\end{array}$ & $\begin{array}{l}\square \text { Lifestyle ch } \\
\square \text { TCM } \\
\square \text { Sacral nerve }\end{array}$ & $\begin{array}{l}\text { hanging } \quad \square \mathrm{W} \\
\quad \square \mathrm{En} \\
\text { e stimulation }\end{array}$ & $\begin{array}{l}\text { it and watch } \\
\text { ema } \\
\text { surgery }\end{array}$ \\
\hline
\end{tabular}

\section{Figure 1}

Questionnaire used to assess colorectal surgeons' awareness and knowledge of LARS 

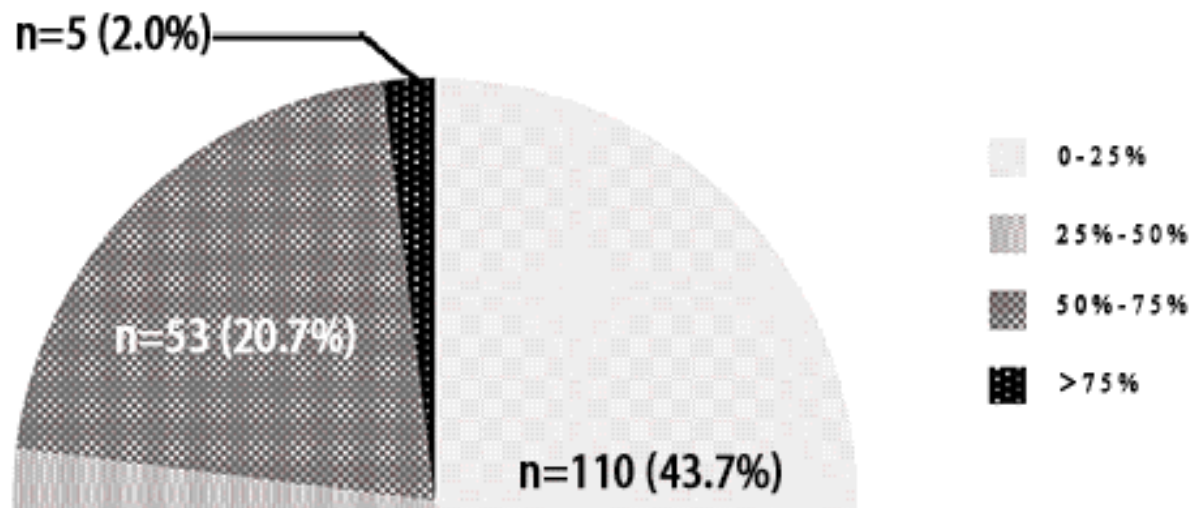

\section{$n=110(43.7 \%)$}

\section{$n=84(32.8 \%)$}

\section{Figure 2}

Prevalence of LARS after LAR estimated by Chinese colorectal surgeons $(n=252)$

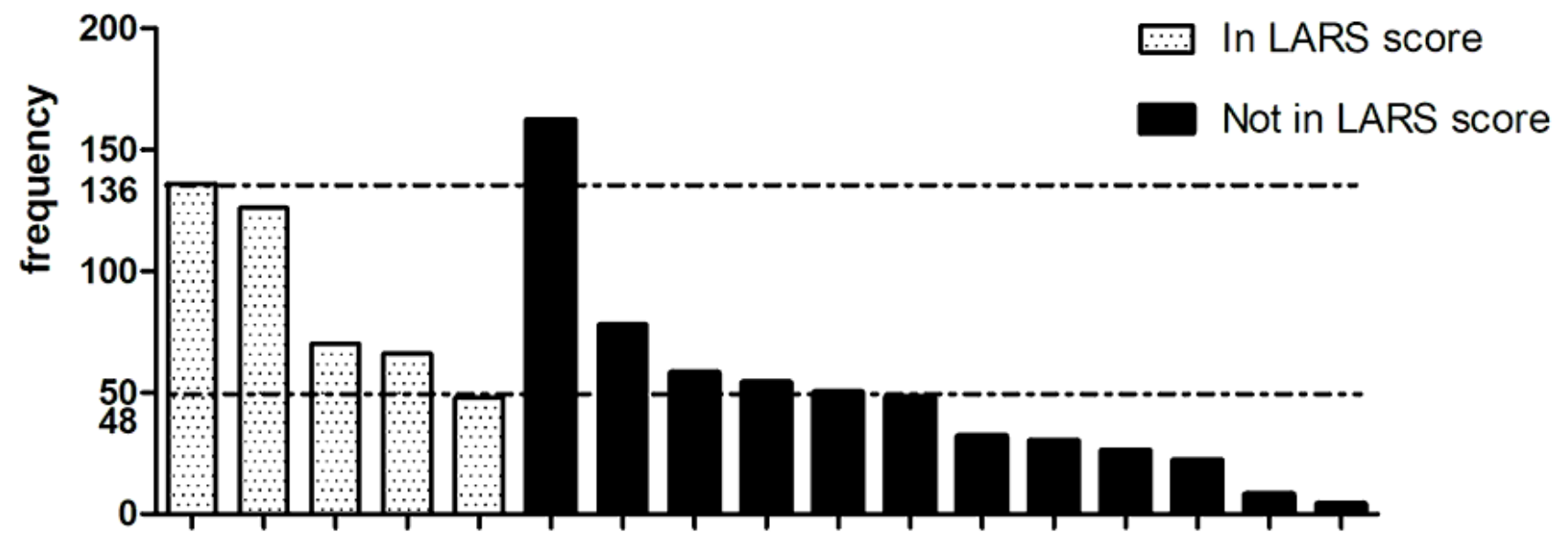

Figure 3 
Frequency of 17 anorectal disorders chosen by respondents $(n=252)$ The first five issue were in LARS score, the last twelve issue were not listed in LARS score. The order of issues in questionnaires were random, and they were rearranged according the cumulative frequencies.

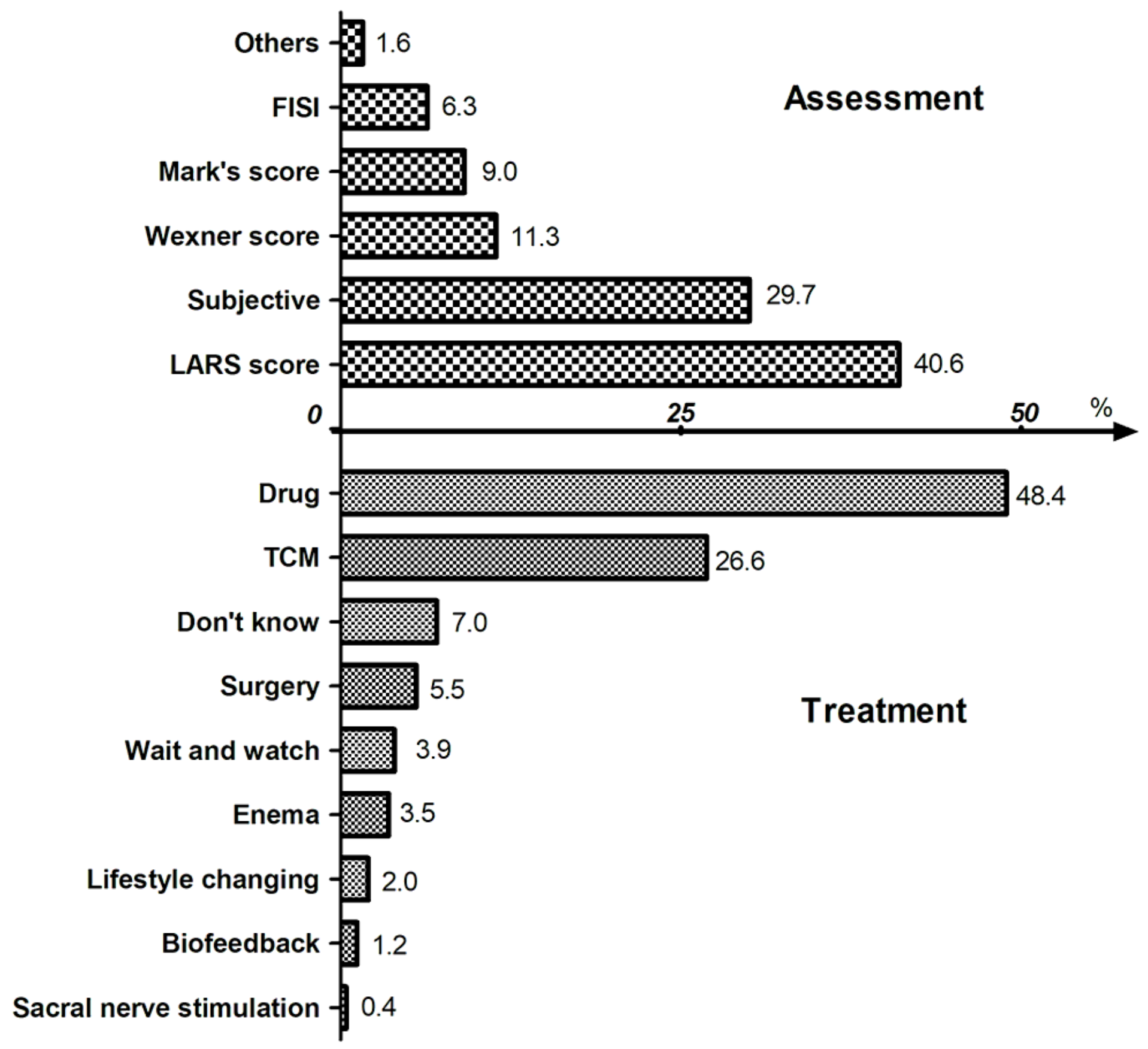

Figure 4

Assessment and treatment of LARS chosen by respondents $(n=252)$ Only one option can be selected. The order of issues in questionnaires were random, and they were rearranged according to the cumulative percentage. 


\section{Supplementary Files}

This is a list of supplementary files associated with this preprint. Click to download.

- questionnaire.pdf 